\title{
"Caries Experience Among 3-5 years Cleft Lip / Cleft Palate Patients, at Jain Hospital, Bangalore."
}

\author{
Dr Rashmi. $M^{1}$, Dr Satish Yadav T ${ }^{2}$, Dr Chandrakala J. ${ }^{3}$ \\ ${ }^{I}$ Senior Lecturer, Dept of Public Health Dentistry, KGF college of Dental Sciences\& Hospital, Kolar, \\ Karnataka, India. \\ ${ }^{2}$ Assistant Professor, Dept of Oral and Maxillofacial Pathology, Government Dental College\& Research \\ Institute, Bangalore, Karnataka, India. \\ ${ }^{3}$ Associate Professor, Dept of Oral and Maxillofacial Pathology, Government Dental College \&Research \\ Institute, Bangalore, Karnataka, India.
}

\begin{abstract}
:
Aim : To assess the prevalence of dental caries among cleft lip / cleft palate patients in 3-5 years of age, at Jain Hospital.

Methods: The study sample consisted of 100 children visiting Jain Hospital Bangalore in the age group of 3 to 5 years. Dental caries status was recorded using dmfs index by Grubbel.A.O.

Results: Fifty percent of the children had caries and was significantly greater in cleft subjects (64\%), than (36\%) in the noncleft subjects. Sex wise comparison revealed that caries prevalence in males was $44 \%$, \& in females $56 \%$ and the difference was significant statistically $(P<0.05)$. Mean ds score (2.23) was higher in females compared to males (0.98). Mean dmfs score (3.36) was also higher in cleft subjects compared to non cleft subjects (2.52).

Conclusion: It is very important to promote awareness of oral health among cleft patients and integrate dental preventive regimens into the treatment protocol.
\end{abstract}

Key words: Cleft Lip/Palate Patients, Children, DMFT, DMFS

List of Abbreviations

\begin{tabular}{|c|c|c|}
\hline Sl. no & Abbreviation & Full form \\
\hline 1 & DMFT & Decayed, Missing, Filled, Teeth \\
\hline 2 & DMFS & Decayed, Missing, Filled, Surfaces \\
\hline 3 & DS & Decayed Surfaces due to caries \\
\hline 4 & FS & Filled Surfaces due to caries \\
\hline 5 & MS & Missing Surfaces due to caries \\
\hline 6 & Dmft & decayed, missing, filled, teeth \\
\hline 7 & Dmfs & decayed, missing, filled, surfaces \\
\hline 8 & Ds & decayed surfaces due to caries \\
\hline 9 & Fs & filled surfaces due to caries \\
\hline 10 & Ms & missing surfaces due to caries \\
\hline 11 & CLP & Cleft lip/palate \\
\hline 12 & ECC & Early childhood caries \\
\hline
\end{tabular}

\section{Introduction}

A cleft is a congenital space or gap in the upper lip, alveolus or palate. It is a structural correctable defect that usually affects upper lip, alveolus or palate \& other functional areas depending on the extent of the cleft defect. This condition is commonly known as "harelip". Facial clefts constitute $65 \%$ of the anomalies affecting the head and neck. Cleft lip (cheiloschisis) and cleft palate (palatoschisis), which can also occur together as cleft lip and palate, are variations of a type of clefting congenital deformity caused by abnormal facial development during gestation. (Wan Chun Zhuet al.,2010), (TAHIR PAUL and RON S. BRANDT ,1998) $)^{1,5}$.

Cleft lip and palate is one of the most common deformities in the development of oro-facial structures, affecting approximately 1 in every 700 newborns. The incidence of cleft lip and palate has been reported as 1.12 per 1000 live births; $1.36 / 1000$ in an American white population and 0.54/1000 in the nonwhites and 2.0/1000 live births in Sweden. (Lam L. Cheng, B.D.Sc(Hons) etal ., 2007) , (VICTORIA S. LUCAS etal ., $2000)^{2,3}$. 
A healthy primary dentition in cleft children is essential for the successful outcome of orthodontic treatment, oral function, speech development, and space maintenance for dentition. However, achieving optimal dental health in cleft lip/ palate children may be difficult, due to the anatomy of the cleft area, malaligned teeth, hypoplastic defect, scarring, and the consequences of surgical repair that cause immobility of the lip. Early extraction would result in loss of the bone preserved by primary teeth bordering the alveolar cleft and may also hinder good speech development. A multidisciplinary approach to their management has become more prevalent in recent years and is now the accepted approach. Children with clefts also exhibited poor oral hygiene as well as poor gingival and periodontal conditions. Cleft lip and/or palatepatients have a higher percentage of carious teeth than control subjects, similar results have been shown by several investigators in other countries. (Wan Chun Zhuet al., 2010), (FANNY W. L. WONG and NIGEL M. KING, 1998), (TeerapongMutarai et al., 2008) $)^{1,}$ 4,7 .

The literature revealed that children with oral cleft lip/ palate have a higher risk of developing caries in deciduous dentition than those of similar age without oral cleft lip/ palate. But insufficient data are available on caries experienced by cleft children of preschool age. Moreover, problems have not been properly addressed regarding the studies of dental caries, due to a small sample size, caries prevalence that varied with age, inclusion of syndromic cases, inappropriate or no controls, and failure to eliminate other confounding factors, as was found in other recently published literature (TeerapongMutarai et al., 2008) ${ }^{7}$.

Only sparse data are available from our country on the experience of dental caries in children with oral cleft. Hence an attempt has been made to assess the dental caries experience among 3-5 years children with cleft lip/ palate.

\section{Aim:}

The aim of this study was to assess the prevalence of Dental caries among 3-5 years cleft lip / cleft palate patients, at Jain Hospital"

\section{Methods}

A cross sectional study was conducted to assess the primary dentition status of cleft affected children visiting Jain Hospital Bangalore in the Department of Cleft (Smile Train Programme) and Department of Pediatrics.

Ethical clearancewas obtained,calibration and training ofinvestigator was done in the Department of Public Health Dentistry, Dr. Syamala Reddy Dental College, and Hospital\& Research Center. The results so obtained were subjected to Kappa Statistics. The Kappa co-efficient value for intra-examiner reliability with respect to Dentition status and treatment needs was 0.7 . These values reflected high degree of conformity in observations.

A survey was systematically scheduled for 2 months from $24^{\text {th }}$ February $2010-31^{\text {st }}$ April 2010. A self designed proforma was used for obtaining required general information of every subject and also for recording the required observations.

\subsection{Inclusion and Exclusion Criteria}

- Children with any type of cleft lip/ palate were included in the study.

- Children without any type of cleft lip/ palate were included as non-cleft lip/palate patients in the study.

- Parents who were interested and willing to involve their children to take part in the study were included.

- Children with retardation, serious medical problems, or other congenital malfunctioning were not included in the study.

\subsection{Pilot Study}

A Pilot study was conducted, at Jain Hospital Bangalore in the Department of Cleft (Smile Train Programme) and Department of Pediatrics.Based on the results of the pilot study, some minor modifications were done in the proforma and a convenient sample size was taken as the prevalence of the study population is less.

\subsection{Study population}

Source of data - Patients in Department Of Cleft and Department Of Pediatrics at Jain Hospital were included forthe study.The study sample consisted of 100 (cleft affected and non cleft affected) children visiting Jain Hospital Bangalore in the Department Of Cleft (Smile Train Programme) And Department of Pediatrics, the age group range was 3 to 5 years. In the Department Of Cleft, children underwent dental examination on a dental chair. Using mouth mirror \&CPI probe, decayed, missing, and filled primary teeth were recorded by applying dmfs index by Grubbel .A.O. -1944 . 


\subsection{Statistical Analysis:}

Data was analyzed using the statistical package for social science (SPSS) version $15 \ldots \mathrm{Z}$ test was used to compare the various parameters and to find out the level of significance. A difference was considered to be statistically significant if $\mathbf{p}<\mathbf{0 . 0 5}$.

\section{Results}

A Cross-sectional study was undertaken to assess the primary dentition status of cleft affected children visiting Jain Hospital Bangalore in the Department Of Cleft (Smile Train Programme) And Department of Pediatrics.

Graph I- Shows the Gender distribution among cleft lip/palate patients, out of 50 cleft lip/palate patients, 52\% were males and $48 \%$ were females.

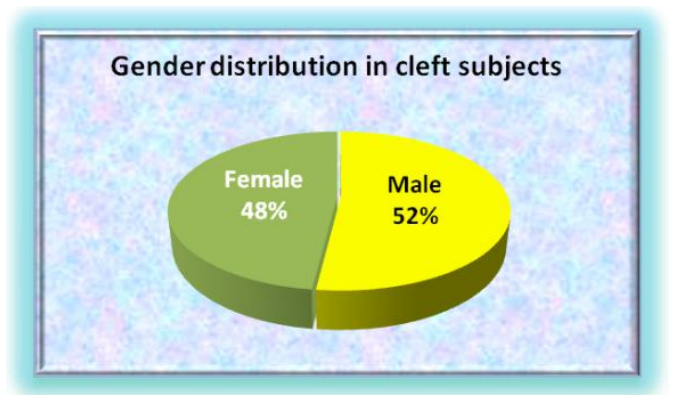

Graph II- Shows the gender distribution among non cleft lip/palate patients, out of 50 non cleft lip/palate patients, $60 \%$ were males and $40 \%$ were females.

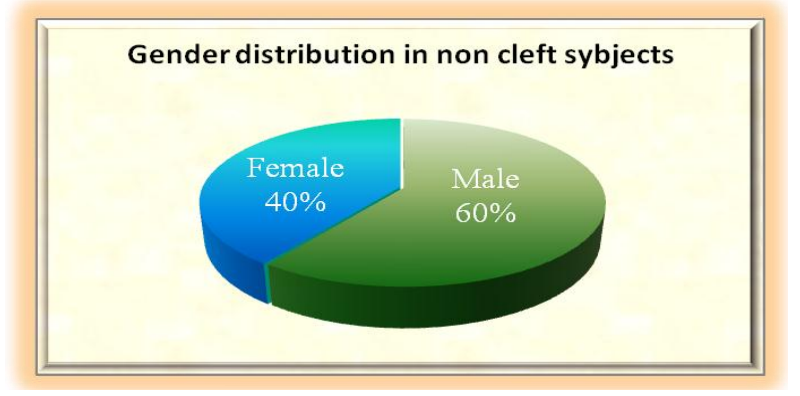

Table I: Shows prevalence of Dental caries among cleft lip/palate and non-cleft lip/palate patients according to gender. Sex wise comparison revealed that caries prevalence in males cleft lip/palate patients was $65 \%, \&$ in females cleft lip/palate patients was $62 \%$ and the difference was significant statistically $(\mathrm{P}<0.05)$.

Caries prevalence in males non cleft lip/palate patients was $26 \%, \&$ in females non cleft lip/palate patients was $5 \%$ and the difference was significant statistically $(\mathrm{P}<0.05)$.

Caries prevalence among males in the study population was $44 \%, \&$ in females it was $56 \%$ and the difference was significant statistically $(\mathrm{P}<0.05)$.

Table I - Prevalence Of Dental Caries Among Cleft Lip/Palate And Non-Cleft Lip/Palate Patients According To Gender

\begin{tabular}{|c|c|c|c|c|c|c|}
\hline \multirow[t]{2}{*}{ Parameters } & \multicolumn{2}{|c|}{ Male } & \multicolumn{2}{|c|}{ Female } & \multirow[t]{2}{*}{$\mathbf{Z}$} & \multirow[t]{2}{*}{ P-value } \\
\hline & $\mathrm{n}$ & $\%$ & $\mathrm{n}$ & $\%$ & & \\
\hline Cleft & 17 & 65 & 15 & 62 & 2.85 & $0.025^{*}$ \\
\hline Non-cleft & 8 & 26 & 10 & 5 & 3.41 & $0.011^{*}$ \\
\hline Total & 25 & 44 & 25 & 56 & 2.41 & $0.037 *$ \\
\hline
\end{tabular}

\section{*denotes significant difference}

Table II: Shows prevalence of Dental caries among cleft lip/palate and non-cleft lip/palate patients. In the present study, the prevalence of caries was high in cleft lip /palate patients (64\%), compared to non cleft lip /palate $(36 \%)$ patients in the 3- 5 year old children .The differences was statistically significant $(\mathrm{P}<0.05)$. Overall Caries prevalence was $50 \%$. 
“Caries Experience Among 3-5 years Cleft Lip / Cleft Palate Patients

Table II- Prevalence Of Dental Caries Among Cleft Lip/Palate And Non-Cleft Lip/Palate Patients

\begin{tabular}{|l|l|l|l|l|}
\hline Parameters & $\mathrm{n}$ & $\%$ & Z & P-value \\
\hline Cleft & 32 & 64 & 2.40 & $0.027^{*}$ \\
\cline { 1 - 3 } Non cleft & 18 & 36 & & \\
\hline Total & 50 & 50 & & \\
\hline
\end{tabular}

*denotes significant difference

Table III: Show the mean value of different parameters in cleft lip/palate and non cleft lip/palate patients. The mean dmfs score was higher in cleft lip/palate patients (3.36) than in non cleft lip/palate patients (2.52), and the difference was significant statistically $(\mathrm{P}<0.05)$

The mean ds score in cleft lip/palate patients was 1.94 and in non cleft lip/palate patients was 1.12. The mean ms score 1.52 was found in cleft lip/palate patients, 1.36 was found in non cleft lip/palate patients. The mean fs score 0.04 was found in cleft lip/palate patients, in non cleft lip/palate patients score was 0.02 . The differences were not significant statistically $(\mathrm{P}>0.05)$.

Table -III- Mean Value And Standard Deviation Of Variables Studied Between Cleft And Non Cleft Patients

\begin{tabular}{|c|c|c|c|c|c|c|}
\hline Parameter & Group & Mean & Std.dev & Mean difference & $\mathbf{Z}$ & P-Value \\
\hline \multirow[t]{2}{*}{ Ds } & cleft patients & 1.94 & 2.65 & \multirow[t]{2}{*}{0.82} & \multirow[t]{2}{*}{-1.938} & \multirow[t]{2}{*}{0.053} \\
\hline & non cleft patients & 1.12 & 1.67 & & & \\
\hline \multirow[t]{2}{*}{ Ms } & cleft patients & 1.52 & 3.22 & \multirow[t]{2}{*}{0.16} & \multirow[t]{2}{*}{-1.339} & \multirow[t]{2}{*}{0.181} \\
\hline & non cleft patients & 1.36 & 4.09 & & & \\
\hline \multirow[t]{2}{*}{ Fs } & cleft patients & 0.04 & 0.28 & \multirow[t]{2}{*}{0.02} & \multirow[t]{2}{*}{-0.014} & \multirow[t]{2}{*}{0.989} \\
\hline & non cleft patients & 0.02 & 0.14 & & & \\
\hline \multirow[t]{2}{*}{ Dmfs } & cleft patients & 3.36 & 4.62 & \multirow[t]{2}{*}{0.84} & \multirow[t]{2}{*}{-2.082} & \multirow[t]{2}{*}{$0.037 *$} \\
\hline & non cleft patients & 2.52 & 4.99 & & & \\
\hline
\end{tabular}

*denotes significant difference

Table IV: Shows the mean value of different parameters between males and females. The mean dmfs score was high in females (3.36) than males (2.36) but the difference was not significant statistically $(\mathrm{P}>0.05)$.

The mean ds score was high in females (2.23) than males (0.98) and the difference between them was statistically significant $(\mathrm{P}<0.05)$

The mean ms score in females was 1.55 , in males 1.36 . The mean fs score in males was 0.04 which was slightly high compared to females (0.02). The differences were not significant statistically $(\mathrm{P}>0.05)$.

TABLE -IV- MEAN VALUE AND STANDARD DEVIATION OF VARIABLES STUDIED BETWEEN MALES AND FEMALES

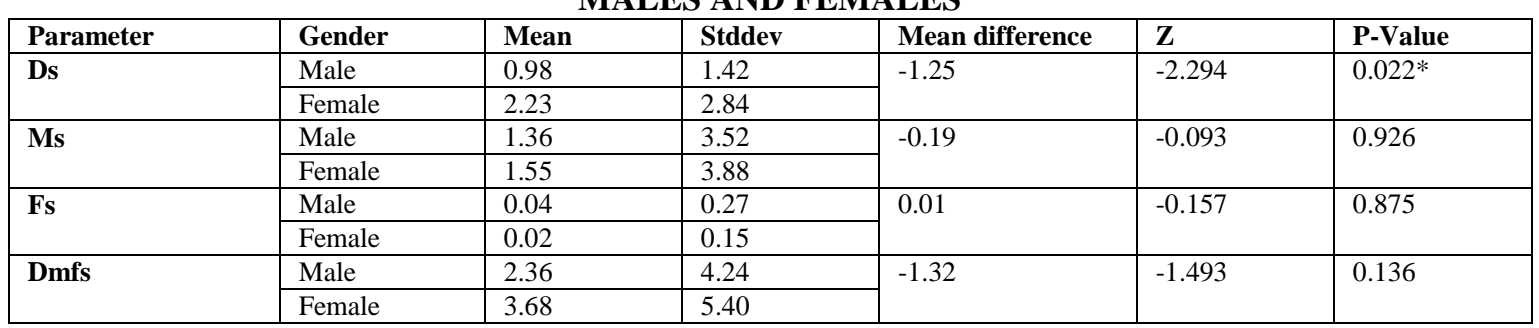

*denotes significant difference

\section{Discussion}

The information on the prevalence of dental caries among children with oral clefts, in India is sparse. The present study sample size consisted of 100 (cleft affected and non cleft affected) children visiting The Jain Hospital Bangalore in the Department Of Cleft (Smile Train Programme) And Department of Pediatrics, the age group range was 3 to 5 years. The small sample size in the study might be due to narrow age range, low prevalence of cleft lip/palate and due to time constrain and this was comparable with other studies.Prevalence of cleft lip / cleft palate is reported to range from 1 in every 700 new births in India, 0.91 to 2.69 per 1000 in Caucasians and from 0.85 to 2.68 per 1000 in Japanese. Therefore, epidemiological studies involving CLP subjects rarely have an adequate-sized sample or a narrow enough age range to produce valid statistics. A representative sample is especially important if dental caries is being studied because of the multifactorial nature of the disease; furthermore, it varies with age and there are secular trends. These limitations have been demonstrated in other studies(FANNY W. L. WONG and NIGEL M. KING, 1998), ${ }^{4}$. 
Overall caries prevalence among study population was $50 \%$, Sex wise comparison revealed that caries prevalence in males cleft lip/palate patients was $65 \%, \&$ in females cleft lip/palate patients was $62 \%$ and the difference was significant statistically $(\mathrm{P}<0.05)$.

Caries prevalence in males non cleft lip/palate patients was $26 \%$, \& in females non cleft lip/palate patients was $5 \%$ and the difference was significant statistically $(\mathrm{P}<0.05)$.

Caries prevalence among males in the study population was $44 \%, \&$ in females it was $56 \%$ and the difference was significant statistically $(\mathrm{P}<0.05)$. Further research is necessary to corroborate these findings and determine the cause.

In the present study, the prevalence of caries was high in cleft lip /palate patients (64\%), compared to non cleft lip /palate (36\%) patients in the 3- to 5-year-old group. The differences was statistically significant $(\mathrm{P}<0.05)$. Similar findings were observed by Wan Chun Zhu (2010) in China ${ }^{1}$, caries prevalence among cleft subjects was $70.93 \%$ and $66.8 \%$ in non cleft subjects among 3- to 5-year-old children. The differences was statistically significant $(\mathrm{P}<0.05)$.

In the present study the percentage (64\%) of cleft lip/palate patients having dental caries is considerably higher compared to a study done by United Kingdom Child Dental Health Survey for 5-year-olds (O'Brien, 1994) (50\%). The reason for high prevalence in present study might be because, parents are more interested in treating the cleft than maintaining good oral health of their children (TAHIR PAUL and RON S. BRANDT, 1998$)^{5}$.

When compared with individuals with cleft lip and/ or palate in other countries, China had more decayed teeth than those in England (Paul and Brand, 1998) but fewer than those in Russia (Turner et al., 1998), Jordan (AlWahadni et al., 2005), and Southern Vietnam (Besseling and Dubois, 2004). This may be accounted for by race, diet or feeding habits, and socioeconomic status in the different studies (Wan Chun Zhu ,2010) in China ${ }^{1 .}$

There was significant difference in the mean dmfs between the children with cleft lip/palate patients \& non cleft lip/palate patients. The mean dmfs score (3.36) found in cleft lip/palate patients was slightly high compared to non cleft lip/palate patients (2.52). The difference was found to be statistically significant. Lages et al (2004) (Wan Chun Zhu (2010) in China) observed that the dmft was 2.91in cleft lip /palate patients in the 1- to 5-year-old age group. The results of the present study was high compared to later study , that may be because the parents are more concerned with other aspects of care,(ie ., surgery and speech development so that dental restorative care is not a priority unless the child has discomfort ).

The mean dmfs values for the children with cleft lip and palate in the present study was 3.6 which was more when comparing the range of dmfs in the Great Britain survey which was 1.2 to 2.8 (Pitts and Palmer, 1994), with a local dental survey in Greenwich, an inner-city area of London, which was 2.4 (Ob, 1994). The discrepancy in the results may be due to the following reasons. First, the prevalence of dental caries in children is possibly in decline, in Great Britain. Second, parents may take more active interest in maintaining good oral health of their children because of their cleft condition. More research is needed to clarify the reasons for increase in mean dmfs in our study (Wan Chun Zhu (2010) in China) ${ }^{1}$. There was no significant difference in the mean dmfs between the male and female patients. Further the decayed element of dmfs showed slightly high mean ds score (2.23) in females when compared to males (0.98) \& the difference between them was statistically significant. Further research is necessary to corroborate these findings and determine the cause.

The results of the present study indicates, the enormity of oral health problems in cleft lip/palate children in 3-5years age group. But, there are many factors which have not been considered in the present study. Therefore, further studies should be addressed regarding the caries prevalence that varied with age, gender, inclusion of syndromic cases, controls, and eliminate other confounding factors, as was found in other recently published literature(FANNY W. L. WONG and NIGEL M. KING, 1998), .

\section{Conclusion}

To conclusion this study showed that children with clefts can be considered as a group having an increased risk of caries. They need both preventive and restorative oral health care. Patients and their families are usually preoccupied with other aspects of care, focusing more on the numerous surgical procedures required to correct the birth defect, so needed early dental care is neglected. It is thus very important to promote awareness of oral health within this population and integrate dental preventive regimens into the treatment protocol.

\section{Recommendations}

- More number of studies should be conducted to obtain base line data

- Strictoral health education programs should be conducted for parents of cleft lip and/or palate patients.

- The implementation of dental caries preventive programs for cleft lip and/or palate patients should be conducted. 


\section{References}

[1] Wan Chun Zhu, M.S., Jin Xiao, Ph.D., Yuan Liu, Ph.D., Jun Wu, Ph.D., JiYao Li, Ph.D. Caries Experience in Individuals With Cleft Lip and/or Palate in China. Cleft Palate-Craniofacial Journal, January 2010, Vol. 47 No. 1; 43- 47.

[2] Lam L. Cheng, B.D.Sc(Hons) etal Predisposing Factors to Dental Caries in Children With Cleft Lip and Palate: A Review and Strategies for Early Prevention Cleft Palate-Craniofacial Journal, January 2007, Vol. 44 No. 1; 67-72

[3] VICTORIA S. LUCAS etal, Dental Health Indices and Caries Associated Microflora in Children With Unilateral Cleft Lip and Palate Cleft Palate-Craniofacial Journal, September 2000, Vol. 37 No. 5; 447- 452.

[4] FANNY W. L. WONG, NIGEL M. KING,A The Oral Health of Children with Clefts-A Review Cleft Palate-Craniofacial Journal, May 1998, Vol. 35 No. 3 248-254

[5] TAHIR PAUL, RON S. BRANDT Oral and Dental Health Status of Children with Cleft Lip and/or Palate Cleft Palate-Craniofacial Journal, July 1998, Vol. 35 No. 4; 329-332.

[6] Goren Dahllofetal, Caries, gingivitis and dental abnormalities in Preschool Children with Cleft lip/palate. Cleft Palate Journal, July 1989, 26,233- 238 .

[7] TeerapongMutarai, WipapunRitthagol, JaranyaHunsrisakhun, Factors Influencing Early Childhood Caries of Cleft Lip and/or Palate Children Aged 18 to 36 Months in Southern Thailand Cleft Palate-Craniofacial Journal, September 2008, Vol. 45 No. 5; $468-472$.

[8] ANKOLA A. V.a, NAGESH L.b, HEGDE P.c, KARIBASAPPA G. N.d Primary dentition status and treatment needs of children with cleft lip and/or palateJ Indian SocPedodPrev Dent- June $2005 ; 80-82$.

[9] David, Morris, Dental caries of primary incisors in children with Cleft lip and palate . Cleft Palate Journal, April 1984, 21 104109.

[10] SJOBBE BESSELING, M.SC. LEANDER DUBOIS, M.SC .The Prevalence of Caries in Children With a Cleft Lip and/or Palate in Southern VietnamCleft Palate-Craniofacial Journal, November 2004, Vol. 41 No. 6; 629- 632.

[11] Mahmoud Al-Dajani, Comparison of Dental Caries Prevalence in Patients With Cleft Lip and/or Palate and Their Sibling Controls, Cleft Palate-Craniofacial Journal, September 2009, Vol. 46 No. 5; 529-531.

[12] J.R. CHAPPLE,.J.H. NUNN, The Oral Health of Children With Clefts of the Lip, Palate, or Both Cleft Palate-Craniofacial Journal, September 2001, Vol. 38 No. 5;525-528. 